\title{
Optimizing the Teaching Strategies of the Novice, Proficient and Expert College English Teachers
}

\author{
Jiafeng Liu ${ }^{1,2}$, Qingshun He${ }^{1}$ \\ ${ }^{1}$ Guangdong University of Foreign Studies, Guangzhou, China \\ ${ }^{2}$ Southwest University for Nationalities, Chengdu, China \\ Email: Janet27@21cn.com
}

Received 17 May 2014; revised 17 June 2014; accepted 25 June 2014

Copyright (C) 2014 by authors and Scientific Research Publishing Inc.

This work is licensed under the Creative Commons Attribution International License (CC BY). http://creativecommons.org/licenses/by/4.0/

c) (i) Open Access

\begin{abstract}
The teaching strategy plays an important part in the effectiveness of the college English teaching. After comparing the current college English teaching strategies in China, this paper attempts to analyze the process teaching strategies and the cognitive teaching strategies of the novice, the proficient and the expert college English teachers at different teaching stages of teaching and proposes the optimizing path of the teaching strategies. This helps make up for the lack of research of enhancing the college English teaching strategies in China.
\end{abstract}

Keywords

Teaching Strategy, College English Teacher, Optimizing Path, China

\section{Introduction}

The teaching strategy is a series of systematic behaviors of the teacher in the teaching process. It includes a theory and a method aiming to solve a certain practical teaching problem (Zhang, 2011). Therefore, the teaching strategy plays an important part in the effectiveness of teaching. What a teaching strategy is to be adopted by the teacher depends on the specific subject, the students and the teacher in specific times. With the transfer of the focus of today's teaching research from "how to teach" to "how to learn", in the Chinese college English teaching process, the Chinese students are becoming active knowledge explorers and the role of the Chinese teacher is to help create a situation conducive to the students' individual exploration. There is a growing concern about the impact of the match of teaching and learning on the Chinese students' achievement. Meanwhile, the rapid development of the information technology has led to great changes of teaching environment and teaching tools 
taking place. This in turn requires the change of the college English teaching strategies with time. Therefore, to understand the teaching strategies used by college English teachers in China and to help them optimize them are not only inevitable in today's society but also an objective requirement to improve the Chinese college students' English proficiency. However, relevant research shows that in college English teaching many Chinese teachers still stick to the traditional teaching strategies, resulting in the unsatisfactory teaching effects. Then, what teaching strategies should the present college English teachers adopt? Do different types of college English teachers choose different teaching strategies? And how can their teaching strategies be optimized? In this article, we will review the present college English teachers' teaching strategies in China, classify the college English teachers into different types from two dimensions of the length of teaching and the professional titles, compare the advantages and disadvantages of the teaching strategies used by different types of teachers, and then put forward the path to optimize their teaching strategies.

\section{Literature Review}

\section{The Current Situation of College English Teaching Strategies}

Of all the college English teachers in China, those holding a doctoral or master's degree account for $1.5 \%$ and $60.1 \%$ respectively and those with a professional title of professor or associate professor, $3.3 \%$ and $22.6 \%$ respectively up to 2010 (Wang \& Wang, 2011). Most of the young college English teachers have good command of English, but they are not experienced in teaching. They have no systematic teaching theories or strategies, hence unsatisfactory teaching achievements. Only can a small number of very outstanding college English teachers meet the students' requirement with satisfactory achievements.

The existing studies of college English teaching strategies in China mainly focus on the teaching process, the teachers' knowledge structure, the teaching content, the match and mismatch of teaching and learning and the selection of teaching tools. As for the teaching process, Zhang (2011) proposes eight classroom college English teaching strategies. That is, the grammar-translation and listening oriented approach, one of the most traditional English teaching strategies in China; the whole language approach, an English teaching strategy in the study of second language acquisition; the cognitive teaching approach, an English teaching strategy under the guidance of Psychological Linguistics; the communicative teaching approach, an English teaching strategy under the guidance of communication and social practice; the content-based approach, an English teaching strategy suitable for professional English teaching; the materialized and humanized approach, an English teaching strategy ignored in the college English classroom; the autonomous learning approach, a task-driven teaching strategy; the dynamic generation and feedback approach. Zhong (2000) discusses the impact of the Chinese teachers' knowledge structure on the teaching strategies and the construction of appropriate knowledge structures. The research shows that the Chinese teachers' strategic knowledge structure changes with their length of teaching and suggests on how to improve the Chinese teachers' strategic knowledge structure. The present studies focus only on some certain professional teaching strategies. For example, Lin (2006) proposes the cultural strategy in foreign language teaching in China. Wu and Wang (2009) study the match of learning and teaching styles in some Chinese universities of science and technology, focusing on the relationship between the teaching and learning strategies. Lu et al. (2009) put forward eight cognitive types of college English teaching strategies, i.e., the action type, the reflection type, the fact-based type, the theory-based type, the vision type, the speech type, the linear type and the global type, and explores the interactions and compensations of the eight types of strategies in dealing with the style mismatch. Lu (2006) discusses the relationship between the English learning styles and the correspondent teaching strategies in Chinese classrooms. Huang (2012) proposes the construction of an English teaching strategy to match the Chinese students' learning styles. As for the selection of teaching tools, the present research focuses mainly on the application of such modern teaching tools as multimedia and network in the Chinese college English teaching. For example, Li (2012) discusses the English teaching strategies in the multimedia environment.

However, no matter from what a perspective, the present studies of the college English teaching strategies in China focus only on some certain aspect or stage of an ideal teaching strategy, paying no attention to the development of the Chinese teachers and the comparison between the college English teachers' process teaching strategies and cognitive teaching strategies at different stages from an overall perspective. Therefore, it is unlikely to put forward a targeted, practically operable optimizing path for the enhancement of the Chinese college English teaching strategies. 


\section{Types of College English Teachers in China}

Berliner (1998) argues that the teachers develop from a novice teacher, through an outstanding novice teacher to a competent, experienced and expert teacher. According to the teachers' knowledge structure, experience and cognition, Leinhart (1986) divides the teachers into the novice type and the expert type. An inexperienced teacher can develop into an experienced teacher through teaching practice and training, but "only can a small number of new comers develop into expert teachers" (Lian \& Meng, 2001). According to Zhong and Zhang (2000), the strategic knowledge develops with the length of teaching and the five-year teaching practice is the critical period. This is because "the length of teaching is a reflection of the teachers' experience accumulation and internalization” (Meng et al., 2004), while in the social context of China, a teacher's professional title can largely reflect his ability. Therefore, Meng et al. (2004) distinguish three types of middle school teachers according to their length of teaching and professional titles: the novice type (juniors with 0 - 5 years of teaching), proficient type (intermediates with 6 - 14 years of teaching) and expert type (seniors with more than 15 years of teaching). This classification is in line with the Chinese social background and can clearly reflect the Chinese teachers' development process.

We use the classification of Meng et al. (2004) for reference to classify college English teachers in China into the novice type, the proficient type and the expert type from the dimensions of the length of teaching and the professional title. The three types of Chinese teachers are those having a teaching experience of less than five years with the professional title being teaching assistant, those having a teaching experience of 6 - 14 years with the professional title being lecturer and those having a teaching experience of more than 15 years with the professional title being associate professors or above respectively.

\section{College English Teaching Strategies in China}

Given that the development of teachers is a process of experience accumulation and internalization, we will carry out a comparative analysis of the novice, the proficient and the expert college English teachers to explore the optimizing path of the college English teaching strategies in this section.

\subsection{Novice Teachers in China}

Most of the novice college English teachers in China hold a master's degree. They have basic theoretical knowledge of pedagogy and psychology and are proficient in English and adept at using advanced teaching tools and methods. However, they do not have a reasonable knowledge structure or teaching experience, or a complete theoretical system of education (Fang, 2011). In the teaching process, the novice college English teachers are mostly self-centered, mainly focusing on the effectiveness of teaching. They emphasize on the before-class preparation and hence formulate a complete teaching plan. In their teaching, they will only copy the lesson plans. It is unlikely to adjust their teaching strategies according to the classroom situation and the students' response. After class, they will be busy completing the task of teaching, and so "they have no real after-class reflections (Meng et al., 2004). As for the application of the cognitive teaching strategies, most novice teachers are still dazed about how to match the teaching and learning styles through cognitive theories. The cognitive teaching strategies they use in teaching are often unprompted and are only a summary of their cognitive learning strategies.

\subsection{Proficient Teachers in China}

Most of the proficient college English teachers in China got their teaching positions after graduation from university. Many obtained their master's degree or doctoral degree in work. Since these teachers restart their professional study after a period of teaching, they have a clear aim to solve their problems encountered in working. They have good command of English and their theoretical knowledge on pedagogy and psychology are becoming richer with the accumulation of teaching experience. They are more experienced than the novice college English teachers. According to Meng et al. (2004), the proficient college English teachers are familiar with classroom teaching and have rich teaching experience. As for the teaching strategy, on the one hand, their before-class strategies are fixed because of their teaching experience and hence somewhat inflexible and rigid. On the other hand, with a deep understanding of English teaching, they will pay more attention to the improvement of their teaching ability and college students' learning styles, and they can flexibly adjust their teaching to meet 
the college students' requirement and the change of the classroom situation, and hence they have high level in-class strategies. However, these proficient college English teachers tend to take the effectiveness of classroom teaching as the evaluation criterion. They pay less attention to how to improve their teaching, hence resulting in the insufficient after-class reflection. As for the cognitive teaching strategies, many proficient college English teachers have begun to reflect on their own teaching styles with the requirement of the match of teaching and learning styles, the pursuit of personal development and the organizational pressure. They choose to participate in a variety of professional trainings or improve their education level to better understand and use relevant theories of teaching strategies and to better match their teaching strategies and the college students' learning styles. Thus, they have a higher level ability of classroom regulation and control to better meet the need of the college students and adapt to the teaching environment.

\subsection{Expert Teachers in China}

Expert college English teachers in China have rich teaching experience. They constantly upgrade their qualification, pursue further study both at home and abroad, take part in foreign language training and teaching training of various levels, and focus on the teaching practice and the frontier professional theories. They can integrate and use not only the knowledge of the English language, teaching and practicing but also that of society, culture and experience in their teaching process (Sternberg, 1997). As a result, expert college English teachers are much easier to achieve a better match between their teaching strategies and the college students' learning styles. However, because of their age, expert college English teachers are generally less skilled in mastering and using the modern teaching tools and methods than the young teachers. Their teaching strategies are largely studentcentered, focusing on the effectiveness of the students' achievements. Their before-class preparation is simple and flexible, their in-class teaching is attractive and their after-class evaluation is effective. This is confirmed by Meng et al. (2004). Their study shows that expert teachers are good at formulating the before-class teaching plan and the after-class evaluation and reflection. These are the fundamentals of their teaching strategies.

As analyzed above, the novice, the proficient and the expert college English teachers in China have respective strong and weak points in their college English teaching strategies. Aiming their weak points, the following part tends to discuss how to optimize the college English teaching strategies of the novice, proficient and expert teachers.

\section{Teaching Strategy Optimizing Path}

As mentioned above, in today's English teaching process, the Chinese college students are the active knowledge explorers, and the college English teachers are the organizers helping create an environment for the students. The question is how to optimize the teaching strategies of different types of college English teachers to create such an environment. Based on the observation of the college English teaching strategies and literature review, this paper argues that the college English teachers must make good use of teaching strategies at different stages according to the students' learning process and their individual characteristics based on the theory of the match of teaching and learning and create, present and reflect on the situations. Only in this way can the match of teaching and learning and the teaching effect be achieved. For this purpose, different types of college English teachers should do their own best to optimize the teaching strategies.

\subsection{Optimizing Path of the Novice Teachers}

Although the novice college English teachers have not a reasonable knowledge structure and lack a complete theoretical system of education, they are adept at using advanced modern teaching tools and instruments. Therefore, they can optimize their teaching strategies from the following perspectives.

\subsubsection{Optimizing Knowledge Structures}

The novice college English teachers can choose to continue their study for a doctoral degree on the one hand, and on the other hand, they can learn relevant teaching theories and participate in relevant training classes of teaching theories, to enrich their knowledge of teaching, practicing socio-culture and empiricism, and hence optimize their own knowledge structure. 


\subsubsection{Improving Teaching Strategies}

The college English teaching in China has always a tradition of mentoring, helping and guiding. This is a systematic one-to-one or one-to-many teaching system, which has helped train a large number of excellent college English teachers for the country. Therefore, the novice college English teachers should actively adapt to this teaching system to carefully observe the whole process teaching by the excellent expert teachers, to learn their before-class, in-class and after-class teaching strategies and to explore how to integrate the experts' teaching strategies with their own.

\subsubsection{Matching Teaching and Learning}

Novice college English teachers should listen to the opinions of the students, be familiar with the students' expectations and learning styles, and arrange their teaching contents according to the students' requirement. They should make full use of the advanced modern teaching tools and constantly adjust and explore appropriate methods of teaching for the effective match of teaching and learning.

\subsubsection{Reflecting on Teaching Strategies}

The existing studies show that only through reflection in specific teaching practices can the teachers better understand the teaching theories and how the teaching theories influence their teaching (Xu \& Li, 2012). Although young teachers may always have made full before-class preparation, they will always be confined in their teaching plans and hence difficult to flexibly choose and adjust their teaching strategies according to the teaching situation and the students' reaction and having no scientific after-class reflection. Therefore novice college English teachers need to learn the teaching reflection theories and practice in their teaching process. This on the one hand can help adjust the teaching plan and on the other hand make the teaching practice reasonable and effective.

\subsection{Optimizing Path of the Proficient Teachers}

Proficient college English teachers have many years of teaching experience and they can adjust their teaching strategies according to the classroom situation and students' requirement. However, they have formed their fixed teaching strategies and seldom consider how to improve their teaching. Therefore, they need to optimize their teaching strategies from the following two perspectives.

\subsubsection{Studying the Dynamic College English Teaching Theories}

With the rapid development of society, a variety of advanced teaching theories appear one after another, and the knowledge in various fields upgrades quickly. Clinging to the so-called advanced teaching strategies will result in their rigidity and inflexibility, hence unable to meet the needs of the modern society. Therefore, the proficient college English teachers must get rid of the empiricism and pay attention to the frontier dynamic theories of college English teaching.

\subsubsection{Optimize Teaching Strategies}

By participating in teaching demonstrations, proficient college English teachers may find the advantages and disadvantages of their own before-class, in-class and after-class teaching strategies, and hence make improvement. In understanding and mastering the teaching reflection theories, the proficient college English teachers can expand the scope of reflection. They will not only focus on the success or failure of classroom teaching, but also consider their reasons, and hence optimize their teaching strategies and improve their teaching ability.

\subsection{Optimizing Path of the Expert Teachers}

It can be seen from the current studies that the teaching strategies of the expert college English teachers are relatively mature and should be learned from by the novice and the proficient teachers. However, in this era of information, the rapid development of technology has exerted profound influences on all the aspects of college English teaching and great changes have taken place in the content, idea, method and strategy of college English teaching. Therefore, the expert college English teachers have no reason to stop, but they should keep an eye on the dynamic social development, try their efforts to understand and learn the new theories about foreign language teaching, use the new teaching tools, and update and improve their teaching strategies. 


\section{References}

Berliner, D. C. (1988). The Development of Expertise in Pedagogy. Washington, D.C.: American Association of College for Teacher Education.

Fang, H. (2011). Reflective Teaching: An Effective Approach of Professional Development of English Teachers at Novice Level. Journal of Heilongjiang College of Education, 3, 51-54.

Huang, R. (2012). A Study of Learning Style Theories and English Teaching Strategies. Journal of Changsha University, 1, 141-143.

Leinhart, G. (1986). Expertise in Mathematics Teaching. Educational Leadership, 3, 28-33.

Li, Y. (2012). English Teaching Strategies in the Environment of Multimedia. China Educational Technology \& Equipment, $28,86-87$.

Lian, R., \& Meng, Y. (2001). A Review of the Research of the Expert and Novice Teachers. Journal of Fujian Institute of Socialism, 4, 66-68.

Lin, J. (2006). A Study of Cross-Cultural Teaching Strategy. Foreign Languages and Their Teaching, 4, 31-33.

Lu, F., Zhang, Y., \& Zhao, X. (2009). Compensatory Effect of Big Class Teaching Strategies in Tertiary English Education on the Mismatch of Learning and Teaching Styles. Foreign Languages and Their Teaching, 4, 38-41.

$\mathrm{Lu}, \mathrm{T}$. (2006). A Study on English Language Learning Strategy and some Suggested Teaching Strategies. Journal of Shanxi Agricultural University (Social Science Edition), 4, 427-428.

Meng, Y., Lian, R., \& Guo, C. (2004). Comparative Studies on Teaching Strategy among Novice, Proficient and Expert Teachers. Psychological Development and Education, 4, 70-73.

Sternberg, R. J. (1997). A Prototype View of Expert Teaching. Journal of East China Normal University, 1, $27-37$.

Wang, S., \& Wang, H. (2011). On the State of College English Teaching in China and Its Future Development. Foreign Languages in China, 5, 4-17.

Wu, L., \& Wang, F. (2009). A Study on Correlation between Science and Technology Students' Cognitive Style and Learning Strategy. Foreign Language World, 5, 50-59.

Xu, J., \& Li, B. (2012). A Study of the Teaching Reflections of the College English Teachers in China. Foreign Language World, 4, 6-14.

Zhang, J. (2011). A Study on College English Teaching Strategy: Choice about English Teaching Strategy. Foreign Language and Literature (Bimonthly), 4, 142-144.

Zhong, K., \& Zhang, K. (2000). A Study of the Development of the Teacher's Strategic Knowledge and Its Influence. Psychological Science, 4, 488-490. 
Scientific Research Publishing (SCIRP) is one of the largest Open Access journal publishers. It is currently publishing more than 200 open access, online, peer-reviewed journals covering a wide range of academic disciplines. SCIRP serves the worldwide academic communities and contributes to the progress and application of science with its publication.

Other selected journals from SCIRP are listed as below. Submit your manuscript to us via either submit@scirp.org or Online Submission Portal.
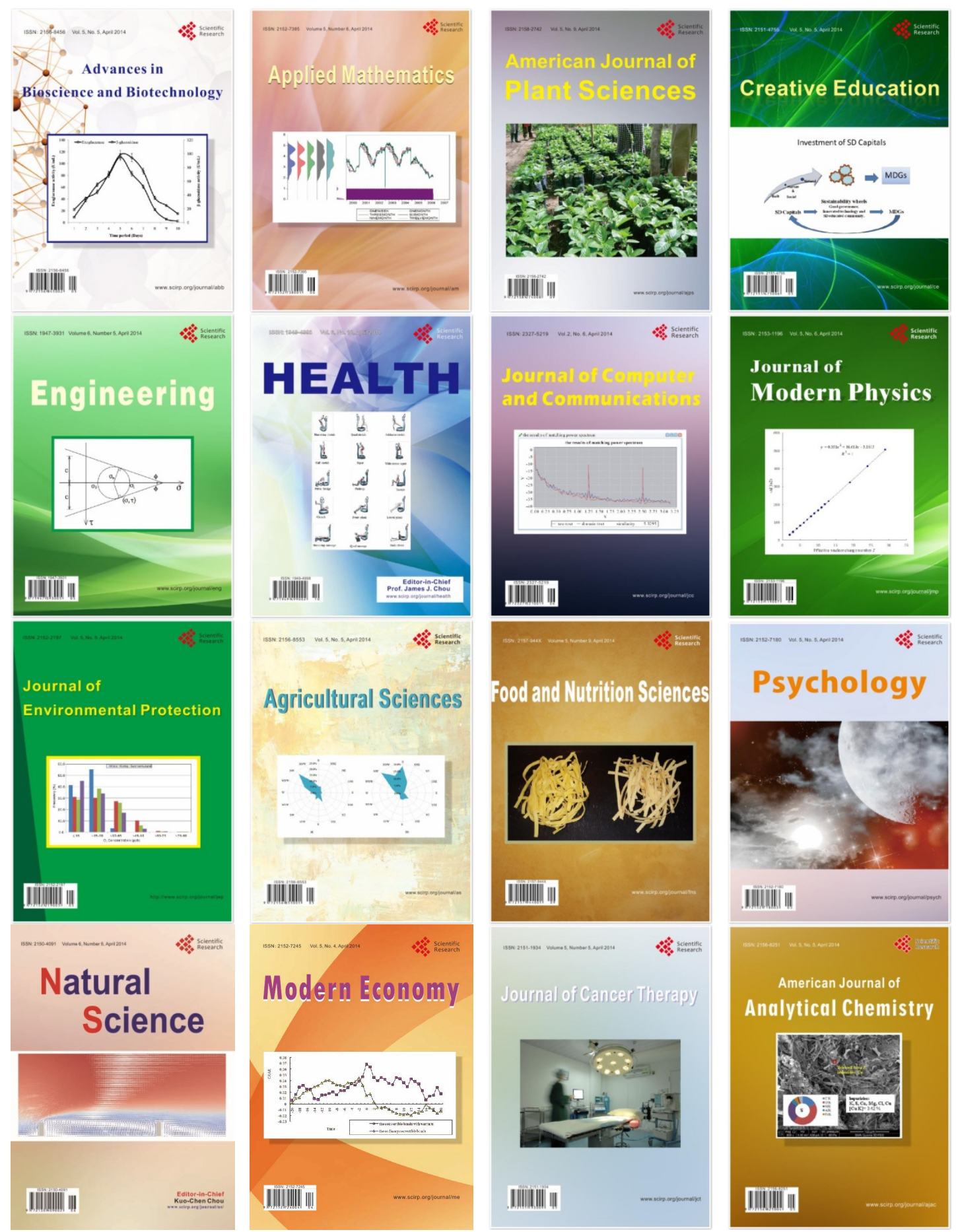